\title{
Influence of additives on the $\boldsymbol{\gamma}$-to- $\boldsymbol{\alpha}$ transformation of alumina
}

\author{
L. A. XUE, I.-W. CHEN \\ Department of Materials Science and Engineering, The University of Michigan, Ann Arbor, MI 48109, USA
}

The transformation of metastable $\gamma-\mathrm{Al}_{2} \mathrm{O}_{3}$ to $\alpha-\mathrm{Al}_{2} \mathrm{O}_{3}$ involves the conversion of cubic close packing of oxygens ions into stable hexagonal close packing [1]. It entails two intermediate transition phases of alumina [1], i.e. $\delta$ and $\theta$, which occur in sequence immediately before converting to $\alpha$. Some metal ions are known to affect the $\gamma$-to- $\alpha$ transformation temperature. For example, $\mathrm{Fe}$ reduces the transition temperature noticeably, whereas $\mathrm{Cr}$ either reduces or raises it slightly depending on the concentration $[2,3] . \mathrm{V}_{2} \mathrm{O}_{5}$, acting as a liquid-phase former, assists the transformation by lowering the transition temperature from 1160 to $1135^{\circ} \mathrm{C}$ [4]. Several other additives ( $\mathrm{Cu}, \mathrm{Mg}, \mathrm{Ni}, \mathrm{Mn}, \mathrm{Ti}$ and $\mathrm{Si}$ ) have also been investigated $[1,5]$, albeit at rather high concentrations (around $10 \mathrm{wt} \%$ ), such that their effects are difficult to compare quantitatively. In the present work we compared the influence of a variety of additives, particularly those forming a liquid phase, at relatively low concentrations ( 1 and $5 \mathrm{~mol} \%$ ), by means of differential thermal analysis (DTA), X-ray diffraction (XRD) and sintering dilatometry studies.

A commercial high-purity, ultrafine $\gamma-\mathrm{Al}_{2} \mathrm{O}_{3}$ powder (Sumitomo AKP-G, > 99.995\%) with a specific surface area of $140 \mathrm{~m}^{2} \mathrm{~g}^{-1}$ was used in this work. The powder was dispersed in distilled water at a $\mathrm{pH}$ of 4 and ultrasonically treated. To the continuously stirred suspension, additives, listed in Table I, were introduced in the form of either aqueous solution (e.g. $\left.\mathrm{Cu}\left(\mathrm{NO}_{3}\right)_{2}\right)$ or ethanol solution (e.g. $\left.\left(\mathrm{C}_{2} \mathrm{H}_{5} \mathrm{O}\right)_{4} \mathrm{Si}\right)$ and the $\mathrm{pH}$ of the mixture was then adjusted to floc the suspension. The slurry was dried and the powder thus obtained was calcined at $700{ }^{\circ} \mathrm{C}$ for $1 \mathrm{~h}$ before use. DTA was employed to determine the transformation temperature in a Netzsch 410 DTA/TG set at a heating rate of $5^{\circ} \mathrm{C} \mathrm{min.}^{-1}$ up to $1310^{\circ} \mathrm{C}$ in air. The weight loss during the experiments was monitored simultaneously to provide information on decomposition of salts at lower temperatures. XRD for powders was conducted, before and after DTA measurement, using a Rigaku Rotaflex diffractometer with Ni-filtered $\mathrm{Cu} K_{\alpha}$ radiation. Shrinkage of compacted powder pellets of $10 \mathrm{~mm}$ diameter and $4 \mathrm{~mm}$ thickness was recorded in a Theta Dilatronic sintering dilatometer at a heating rate of $5^{\circ} \mathrm{C} \min ^{-1}$ up to $1430{ }^{\circ} \mathrm{C}$ in air.

DTA provides an experimentally expedient method for determining the $\gamma$-to- $\alpha$ transformation temperature. Fig. 1 shows three DTA traces, with and without additives ( $\mathrm{B}$ and $\mathrm{Cu}$ ), which clearly illustrates the retardation (in the case of $\mathrm{B}$ additive) and enhancement (in the case of $\mathrm{Cu}$ additive) of the $\gamma$-to- $\alpha$ transformation, occurring around $1200^{\circ} \mathrm{C}$. The broad endothermic peak at a temperature around $60-100^{\circ} \mathrm{C}$ is due to the evaporation of absorbed water, and the broad exothermic hump, spanning from about $150^{\circ} \mathrm{C}$ up to the transformation temperature, appears to be related, at least in part, to the gradual crystallization and coarsening of the starting powder. Similar results were obtained for other additives, as summarized in Table I. The corresponding change of phases was verified by XRD. For example, curve (a) in Fig. 2 shows that for the powder before a DTA run the broad peaks can all be identified with those of $\gamma$-alumina. After the DTA run, only well-defined sharp $\alpha$-alumina

TABLE I Peak transformation temperature, $T_{p}$, from DTA measurements for various additives whose corresponding oxides after the calcination are shown in brackets

\begin{tabular}{|c|c|c|}
\hline Additives & $\begin{array}{l}\text { Concentration } \\
(\mathrm{mol} \%)\end{array}$ & $T_{p}\left({ }^{\circ} \mathrm{C}\right)$ \\
\hline $\begin{array}{l}\text { None } \\
\mathrm{H}_{3} \mathrm{BO}_{3}\left[\mathrm{~B}_{2} \mathrm{O}_{3}\right] \\
\left(\mathrm{C}_{2} \mathrm{H}_{5} \mathrm{O}\right)_{4} \mathrm{Si}_{[}\left[\mathrm{SiO}_{2}\right] \\
\mathrm{ZrOCl}_{2}\left[\mathrm{ZrO}_{2}\right] \\
\left.\mathrm{LiNO} \mathrm{Li}_{2} \mathrm{O}\right] \\
\mathrm{LiF} \\
\mathrm{V}\left(\mathrm{CH}_{3} \mathrm{COCHCOCH}_{3}\right)_{3}\left[\mathrm{~V}_{2} \mathrm{O}_{5}\right] \\
\mathrm{Cu}\left(\mathrm{NO}_{3}\right)_{2} \\
{\left[\mathrm{CuO} / \mathrm{Cu}_{2} \mathrm{O}\right]} \\
\mathrm{Ti}\left[\mathrm{O}\left(\mathrm{CH}_{2}\right)_{3} \mathrm{CH}_{3}\right]_{4}+\mathrm{Mn}\left(\mathrm{NO}_{3}\right)_{2}\left[\mathrm{TiO}_{2}+\mathrm{MnO} / \mathrm{Mn}_{2} \mathrm{O}_{3}\right] \\
\mathrm{Ti}\left[\mathrm{O}\left(\mathrm{CH}_{2}\right)_{3} \mathrm{CH}_{3}\right]_{4}+\mathrm{Cu}\left(\mathrm{NO}_{3}\right)_{2}\left[\mathrm{TiO}_{2}+\mathrm{CuO} / \mathrm{Cu}_{2} \mathrm{O}\right] \\
\mathrm{ZnF}{ }_{2}\end{array}$ & $\begin{array}{l}- \\
1 \\
5 \\
1 \\
1 \\
1 \\
1 \\
1 \\
1 \\
5 \\
1 \text { each } \\
1 \text { each } \\
1 \\
5\end{array}$ & $\begin{array}{r}1216 \\
1254 \\
1258 \\
1268 \\
1291 \\
1215 \\
1212 \\
1190 \\
1185 \\
1114 \\
1171 \\
1149 \\
1035 \\
990\end{array}$ \\
\hline
\end{tabular}




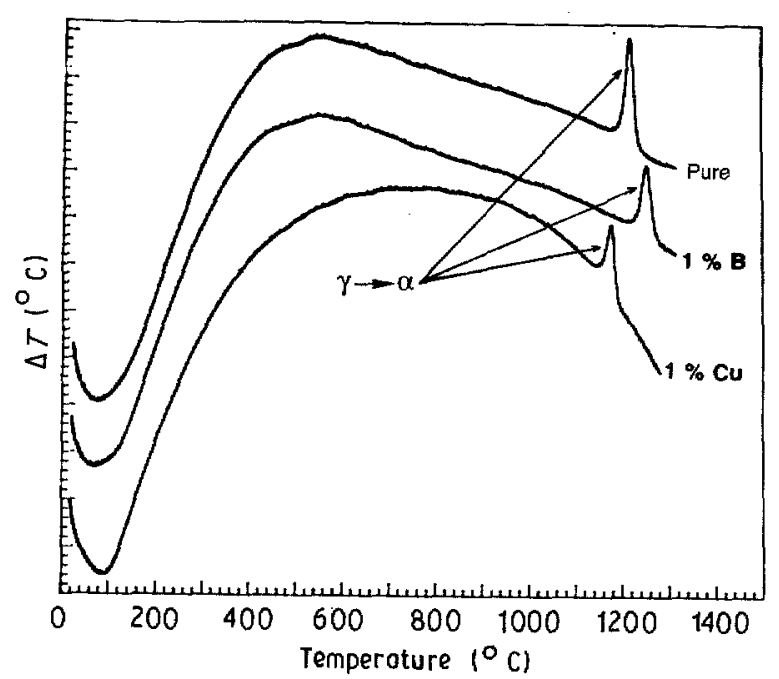

Figure 1 DTA traces for pure, $1 \mathrm{~mol} \%$ B-doped and $1 \mathrm{~mol} \%$ Cu-doped $\gamma$-alumina, at $5^{\circ} \mathrm{C} \min ^{-1}$ in air.

diffraction peaks remain (curve (b))

Among the oxide additives investigated, $\mathrm{ZrO}_{2}$ proves to be the most retarding, with $\mathrm{B}_{2} \mathrm{O}_{3}$ and $\mathrm{SiO}_{2}$ less so. Various transition-metal oxides enhance transformation to a certain extent. However, it is $\mathrm{ZnF}_{2}$ that stands out as the most effective enhancing additive. The latter group of additives $(\mathrm{Zn}, \mathrm{Ti}+\mathrm{Cu}$, $\mathrm{Ti}+\mathrm{Mn}, \mathrm{Cu}, \mathrm{V}$ and $\mathrm{Li}$ ) are thought to form a liquid phase at temperatures below the normal $\gamma$-to- $\alpha$ transformation temperature. Since the $\gamma$-to- $\alpha$ transformation occurs by a nucleation and growth process [6], it may be enhanced by the liquid phase owing to the much increased mass transport via a solutionprecipitation mechanism. Indirect evidence for the liquid-enhanced transportation is provided by the particle morphology of the transformed powders. For example, in Fig. 3 the $\mathrm{Cu}$-doped powder exhibits not only a size of an order of magnitude larger, but also a wider size distribition than those of undoped and B-doped powders. This may be attributed to the liquid phase that forms at $1096{ }^{\circ} \mathrm{C}$ in the

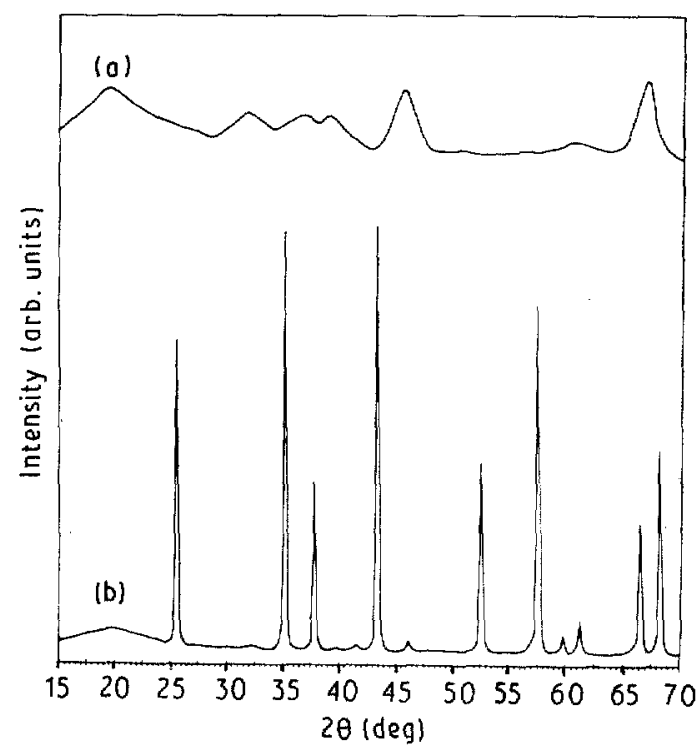

Figure 2 XRD spectra of a $1 \mathrm{~mol} \%$ Si-doped $\gamma$-alumina (a) before and (b) after DTA experiments. Although very broad, peaks of (a) are consistent with a typical $\gamma$-alumina pattern. Spectrum (b) corresponds to a well-crystallized $\alpha$-alumina.

$\mathrm{Al}_{2} \mathrm{O}_{3}-\mathrm{CuO}-\mathrm{Cu}_{2} \mathrm{O}$ system [7]. As a result, $\mathrm{Cu}$ additive assists transformation and also hastens the coarsening of particles. Similar observations have been reported previously for V-doped $\gamma$-alumina [4].

The roles of the three transformation-retarding additives, i.e. $\mathrm{B}, \mathrm{Si}$ and $\mathrm{Zr}$, are less certain. XRD shows that $\mathrm{B}$ addition tends to stabilize $\theta$-phase (an intermediate transition alumina as mentioned above) which can be detected at $>1000{ }^{\circ} \mathrm{C}$ in B-doped powder, thereby delaying nucleation of $\alpha$-phase. However, the origin of this stabilization remains to be identified. In the case of $\mathrm{Zr}$, indications show that $\mathrm{ZrO}_{2}$ precipitates suppress interface reactions of alumina in creep and sintering [8-10]. It may similarly inhibit the transformation by the same mechanism. We have no speculation regarding the possible mechanism by which Si retards transformation, but note the relatively viscous nature of
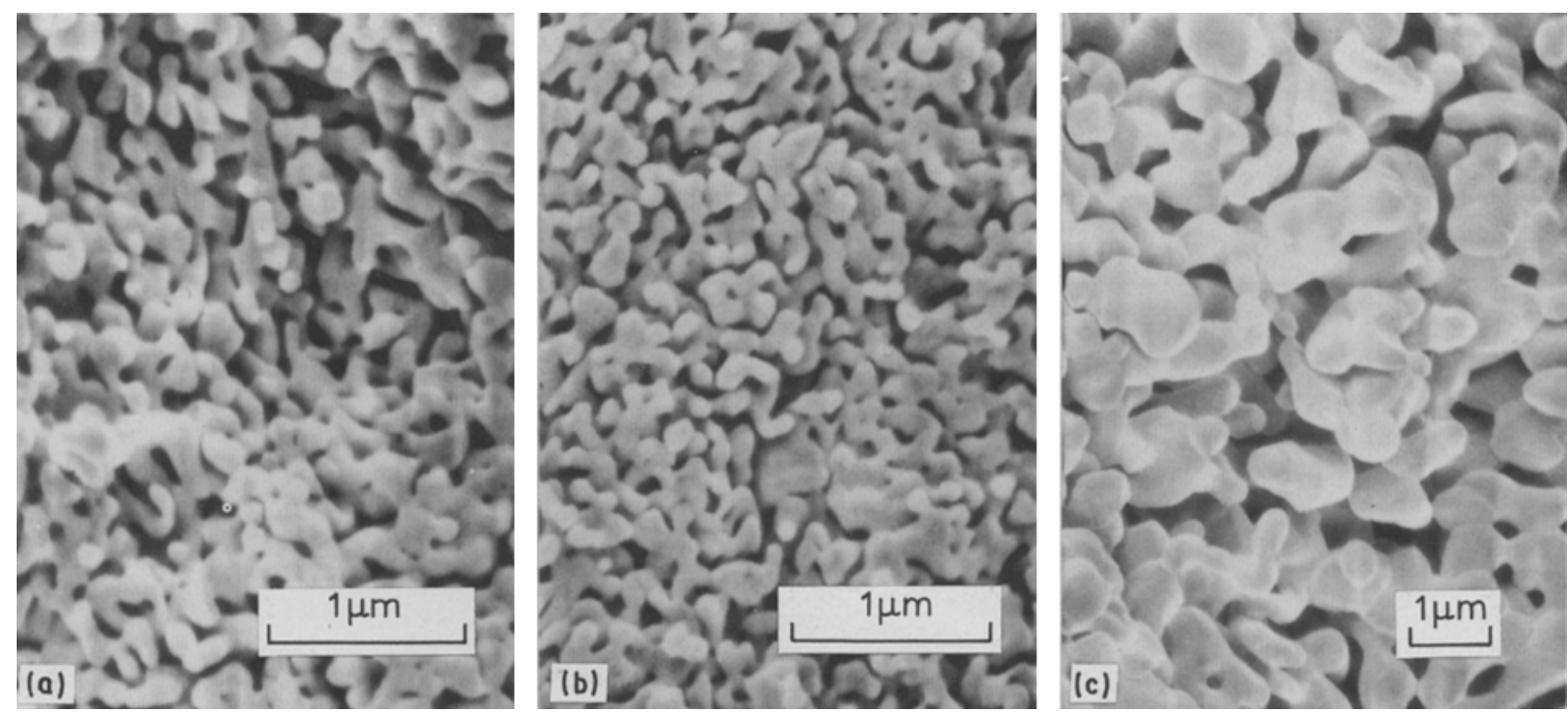

Figure 3 Particle morphology of $\gamma$-alumina powders after DTA: (a) pure, (b) 1 mol $\%$ B-doped and (c) 1 mol \% Cu-doped. They are all transformed $\alpha$-alumina. 
aluminium silicate glass and the refractory nature of the intermediate compound $\mathrm{Si}_{2} \mathrm{Al}_{6} \mathrm{O}_{13}$ (mullite).

Dilatometry studies essentially confirm the same additive effects described above. For example, B addition retards shrinkage/sintering whereas $\mathrm{Cu}$ addition has the opposite effect. Referring to Fig. 4, we note that rapid shrinkage first occurs at a certain temperature, followed by a period of slow sintering, which accelerates again later at a higher temperature. Using XRD, we verified that the first phase of rapid shrinkage was due to $\gamma$-to- $\alpha$ transformation, which was accompanied by a $20 \%$ density change, or a linear shrinkage of about $7 \%$. Interestingly, the actual linear shrinkage in the rapid shrinkage was almost twice this amount. Therefore, reactive sintering stimulated by the phase transformation seems operative here $[11,12]$. It is also interesting to note that, although the additive effects on shrinkage/sintering are generally in agreement with that of DTA data summarized in Table I, the transition temperature recorded for the fast shrinkage consistently occurred at a lower temperature (as much as $100^{\circ} \mathrm{C}$ ) than the peak transformation temperature measured by DTA. The latter observation was in accord with a previous report indicating that compaction of $\gamma$-alumina powder increased the transformation kinetics [6].

In summary, liquid-forming additives enhance the $\gamma$-to- $\alpha$ transformation of alumina. $\mathrm{ZnF}_{2}$ was found to be the strongest enhancing agent. On the other hand, $\mathrm{ZrO}_{2}$ proved to be most effective in retarding the transformation. Additive effects on sintering/ shrinkage were similar except for the added effect of reaction sintering and a faster transformation kinetics due to the better contact between powders in a compact.

\section{Acknowledgement}

This research was supported by the US Army Research Office under Contract No. DAAL0389-L0133.

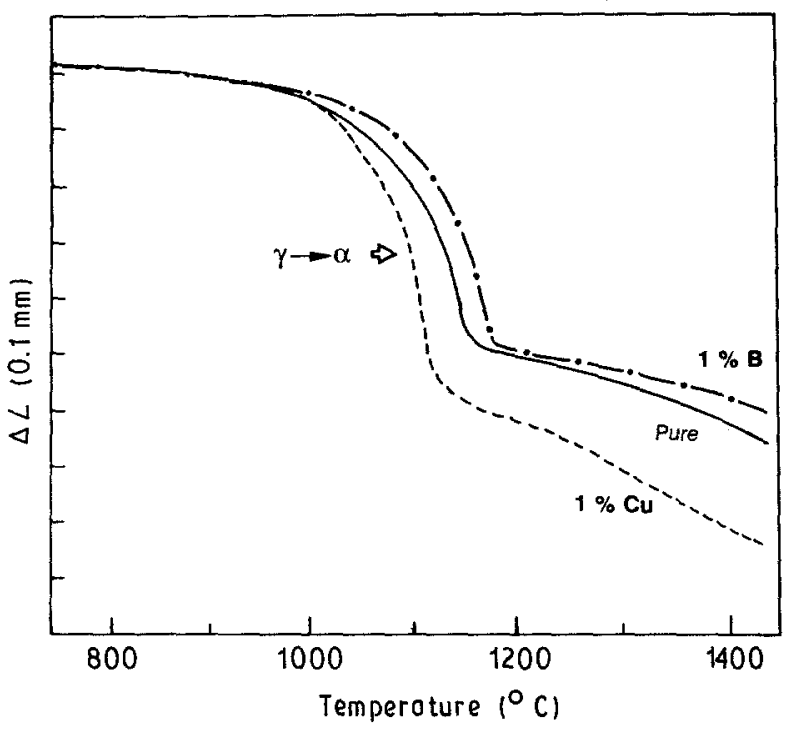

Figure 4 Sintering dilatometer traces for pure, $1 \mathrm{~mol} \%$ B-doped and $1 \mathrm{~mol} \% \mathrm{Cu}$-doped $\gamma$-alumina, at $5^{\circ} \mathrm{C} \mathrm{min}^{-1}$ in air.

\section{References}

1. W. H. GITZEN, "Alumina as a ceramic material", Special Publication No. 4 (American Ceramic Society, Columbus, Ohio, 1970).

2. G. C. BYE and G. T. SIMPKIN, J. Amer. Ceram. Soc. $\mathbf{5 7}$ (1974) 367.

3. T. TSUCHIDA, R. FURUICHI, T. ISHII and K. ITOH, Thermochim. Acta 64 (1983) 337.

4. R. A. SHELleman and G. L. Messing, J. Amer. Ceram. Soc. 71 (1988) 317.

5. Y. WAKAO and T. HIBINO, Nagoya Kogyo Gijutsu Shikensho Hokoku 11 (1962) 588.

6. F, W. DYNYS and J. W. HAlloran, J. Amer. Ceram. Soc. 65 (1982) 442.

7. A. M. GADAlla and J. White, Trans. Brit. Ceram. Soc. 63 (1964) 39.

8. F. WAKAI, T. IGA and T. NAGAno, J. Ceram. Soc. Jpn. 96 (1988) 1206.

9. I. -W. CHEN and L. A. XUE, J. Amer. Ceram. Soc. 73 (1990) 2585.

10. L. A. XUE and I. - W. CHEN, Unpublished work.

11. D. I. MATKIN, W. MUNRO and T. M. VALENTINE, $J$. Mater. Sci. 6 (1971) 974.

12. P. A. BADKAR and J. E. BAILEY, ibid. 11 (1976) 1794.

Received 14 November 1990

and accepted 31 January 1991 